\title{
HONGOS BASIDIOMYCETES: UNA CONTRIBUCIÓN AL CONOCIMIENTO DE 14 GÉNEROS EN NORTE DE SANTANDER
}

Por:

Nancy Jackeline Sánchez Sandoval ${ }^{1}$

\section{RESUMEN}

En el presente trabajo se registran 14 géneros de hongos Basidiomycetes para el Departamento Norte de Santander. Estos géneros pertenecen a 10 familias y 5 órdenes: Agaricales, Boletales, Schizophyllales, Polyporales y Lycoperdales. El último orden perteneciente al grupo conocido comúnmente como Gasteromycetes. El estudio se llevó a cabo en el municipio de Chinácota, durante los años 2003 y 2004.

Palabras Clave: Basidiomycetes, biodiversidad, Norte de Santander, Alto de Mejué.

\section{ABSTRACT}

In this article 14 genera of Basidiomycetes are reported for Norte de Santander Department. These genera belong to 10 families and 5 orders: Agaricales, Boletales, Schizophyllales, Polyporales and Lycoperdales. The last order belongs to Gasteromycetes. The study was done in Chinácota county, during the years 2003-2004.

Key words: Basidiomycetes, biodiversity, Norte de Santander, Alto de Mejué.

\section{INTRODUCCIÓN}

El reino de los hongos, comprende un grupo de organismos versátiles y diversos en su morfología, fisiología, ciclos de vida y ecología. Se parecen a las plantas por poseer pared celular, tomar nutrientes por absorción y ser inmóviles, pero difieren de ellas por no ser fotosintéticos ni autótrofos. Por el hecho de ser heterótrofos y poseer quitina en sus paredes celulares se asemejan a los animales, de los cuales difieren en su modo de nutrición (Franco-Molano et al., 2005) Los hongos son organismos muy valiosos en cuanto a la relación que establecen con el suelo, las plantas y el medio ambiente. Son los agentes principales de la mineralización de la materia orgánica muerta (Llimoná, 2004).

La clase Basidiomycetes se caracteriza porque las esporas se producen en una célula especializada denominada basidio; dicho basidio tiene forma de clava o porra y en su parte superior posee prominencias denominadas esterigmas, sobre los cuales se desarroIlan las esporas, que generalmente se hallan en grupos de cuatro (Alexopoulus, 1985).

Dentro de la clase Basidiomycetes se encuentran diferentes órdenes. Los más comunes encontrados en el presente estudio fueron Agaricales (cuyos cuerpos fructíferos se caracterizan por ser carnosos y presentar un himenóforo con lamelas), Boletales (cuyos cuerpos fructíferos se caracterizan por ser carnosos y presentar un himenóforo con tubos), Polyporales (con cuerpos fructíferos leñosos e himenóforo poroide principalmente), Lycoperdales y Schizophyllales. Los Lycoperdales se ubican dentro del grupo de los Gasteromycetes.

Según Llimoná (2004), el grupo Gasteromycete es un grupo sin categoría taxonómica, que ha tomado este nombre por el aspecto de su carpóforo. En este grupo encontramos todos aquellos hongos Basidiomycotas, que tienen desarrollo angiocárpico, es decir, los basidios maduran siempre en el interior del basidioma y las esporas solo pueden dispersarse en la madurez, al abrirse los basidiomas.

\footnotetext{
'Investigadora principal. Grupo de Investigación Majumba, Dpto. de Biología. Universidad Francisco de Paula Santander - UFPS. najasa71@yahoo.com
} 
Hongos basidiomycetes: Una contribución al conocimiento de 14 géneros en Norte de Santander

Los Gasteromycetes más abundantes pertenecen al orden Lycoperdales y Phallales. Dentro del orden Lycoperdales o Licoperdanas se encuentran aquellos hongos de peridio seco y gleba pulverulenta, el grupo más amplio es el Orden Lycoperdales (unas 270 especies), que forma basidiomas redondeados con o sin pie, protegidos por un peridio delgado en el que se distingue el exoperidio y endoperidio. Los basidios son cortos y presentan esterigmas, largos y desiguales que sostienen esporas pequeñas, redondeadas y ornamentadas. La gleba inmadura es blanca. Todos los Lycoperdales utilizan el impacto de la lluvia, la caída de una rama o fruto, o el paso de un animal, para expulsar las esporas.

En Colombia se han realizado pocos estudios sobre la diversidad de hongos Basidiomycetes. Trabajos como Agaricales de Colombia (Pulido, 1982), Hongos de Antioquia (Velásquez et al., 1998), Setas de Colombia (Franco-Molano et al., 2000) y Macrohongos de la región del medio Cáqueta (Franco-Molano et al., 2005), son los más destacados.

Para el departamento Norte de Santander, no se tiene ningún registro por lo que el grupo de Investigaciones Majumba, inicia el estudio de esta División de hongos en el departamento.

\section{MATERIALES Y MÉTODOS}

En el presente trabajo se registran 14 géneros de hongos Basidiomycetes para el Departamento Norte de Santander. Estos géneros pertenecen a 10 familias y 5 órdenes: Agaricales, Boletales, Schizophyllales, Polyporales y Lycoperdales. El último orden perteneciente al grupo conocido comúnmente como Gasteromycetes. El estudio se llevó a cabo en el municipio de Chinácota, durante los años 2003 y 2004.
El área de estudio se ubica en el bosque de niebla Alto de Mejué, localizado en la vereda Iscalá Sur, del Municipio de Chinácota, Norte de Santander (ver Fig. 1 у 2).

Figura 1. Localización Bosque de Niebla Alto Mejué. Municipio de Chinácota. Departamento Norte de Santander.

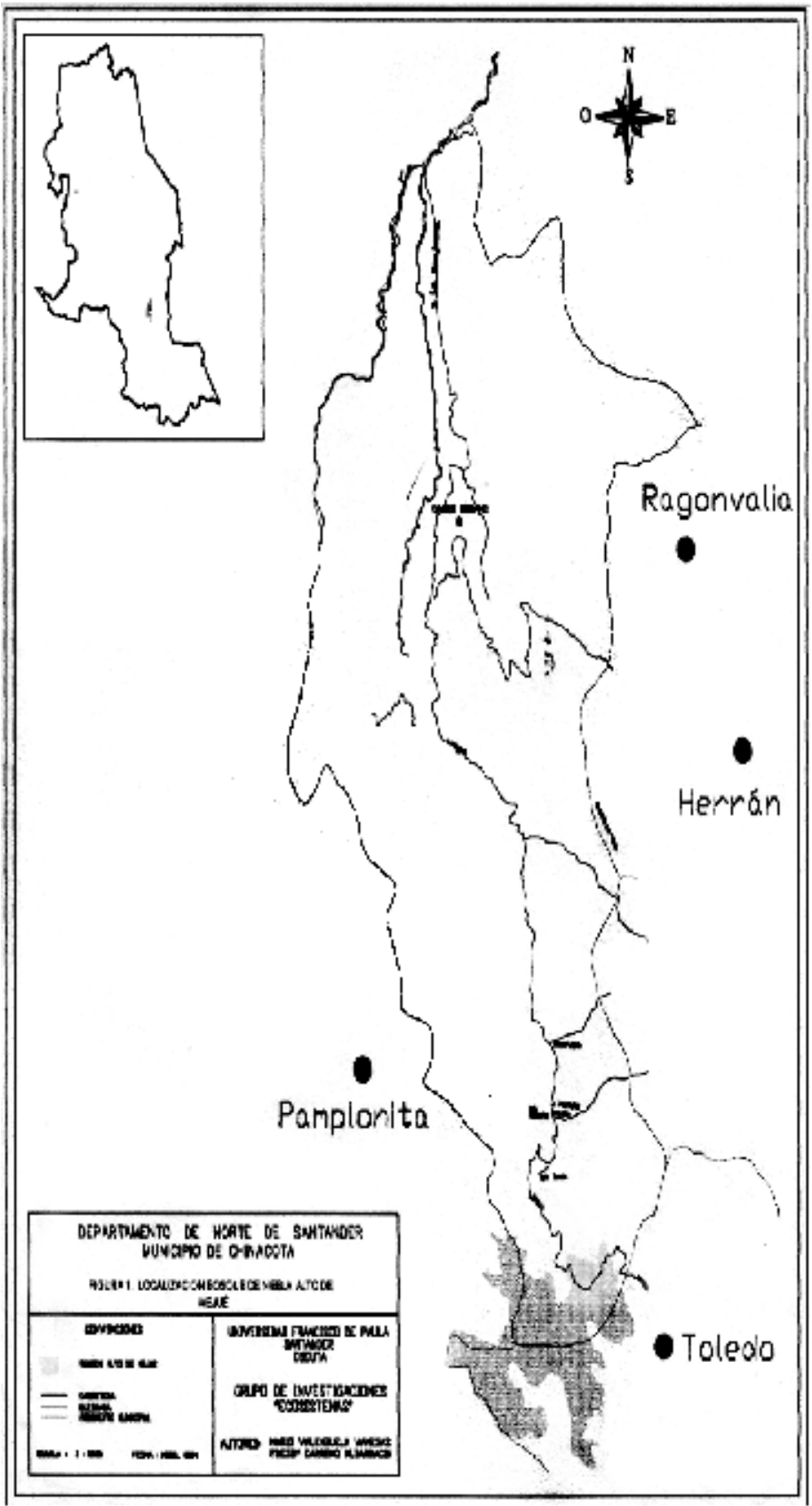

Fuente: Valenzuela et al., 2004. 
Hongos basidiomycetes: Una contribución al conocimiento de 14 géneros en Norte de Santander

Figura 2. Delimitación del área de estudio Bosque de Niebla Alto Mejué.

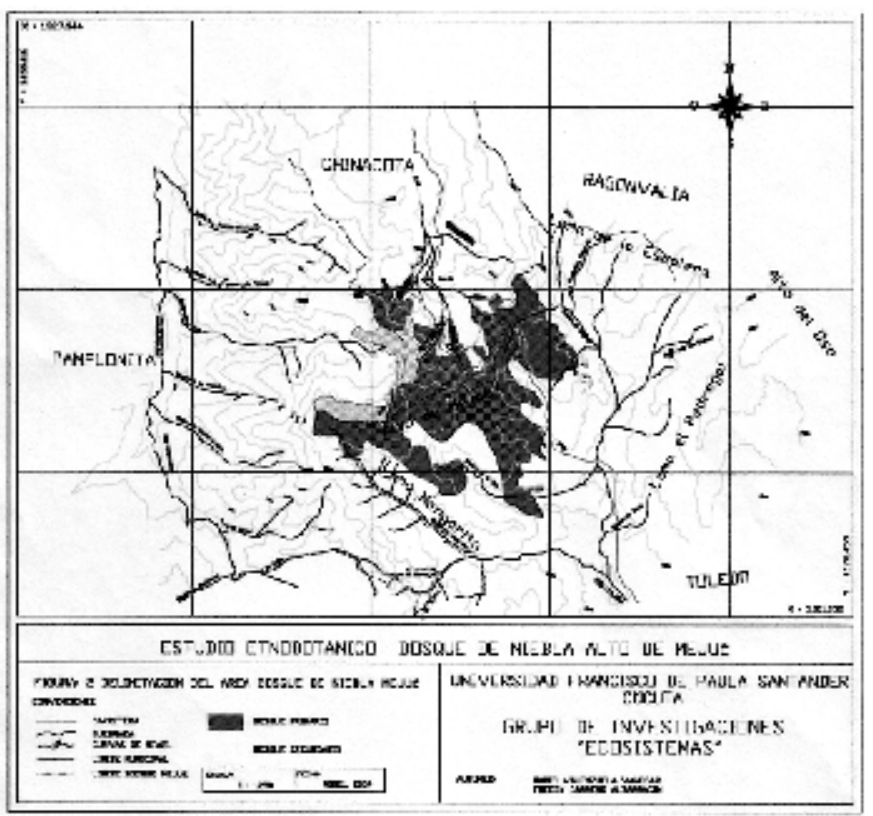

Fuente: Valenzuela, et al., 2004.

Mejué, es una zona de vida cuyo bioma corresponde a un bosque de niebla o bosque húmedo Montano Bajo (bh-MB), según la clasificación de las Zonas de Vida propuesta por Holdridge, (1968). El área también puede ser denominada como bosque Andino si nos apoyamos en la clasificación dada por Cuatrecasas (1958), en la que sitúa la franja boscosa como andina entre los 2.400 y 3.800 metros. En reciente publicación del Instituto Alexander Von Humboldt (1998), se ubica al bosque Andino entre 2.000 y 3.500 m. La máxima altura de este promontorio es aproximadamente de $2850 \mathrm{~m}$ (Valenzuela et al., 2004).

Los muestreos se realizaron durante las estaciones húmedas entre octubre-noviembre de 2003 y abril- mayo 2004; se hicieron alrededor de 6 salidas de campo, colectando los cuerpos fructíferos de un tamaño superior a $4 \mathrm{~cm}$.

En el área se trazaron 3 transectos con un rango altitudinal entre 2300 y 2600 metros así:
Transecto 1: Antiguo Camino real a Pamplona. Se inicia el recorrido en el margen derecho de la carretera que desde Chinácota conduce a Toledo a una altura aproximada de $2450 \mathrm{~m}$. y finaliza sobre el espinazo del cerro a $2590 \mathrm{~m}$.

Transecto 2: Derecho de Vía oleoducto Caño Limón Coveñas. Inicia a la orilla de la carretera a una altura de $2470 \mathrm{~m}$. aproximadamente y finaliza hacia los $2600 \mathrm{~m}$.

Transecto 3: Sendero hacia el tanque que surte el Acueducto Veredal; inicio margen derecho de la carretera que de Chinácota conduce a Toledo, frente a una reja de hierro, a una altura de $2380 \mathrm{~m}$. y finaliza en los alrededores del mencionado tanque a $2430 \mathrm{~m}$.

\section{Muestreos:}

Las muestras fueron recolectadas de acuerdo a la técnica usada por Franco-Molano et al, (2000), y llevadas al laboratorio de botánica de la UFPS para su caracterización y posterior determinación taxonómica.

Se hizo la descripción macroscópica siguiendo la propuesta de Largent (1996) y las pruebas microscópicas de acuerdo a Franco-Molano (2000). Las colecciones se secaron con aire caliente y se empacarom debidamente etiquetadas para su estudio microscópico y posterior determinación con ayuda de las claves especializadas. (Castro, 2003: Largent et al, 2000).

\section{RESULTADOS Y DISCUSIÓN}

Se recolectaron 49 especimenes de las cuales 26 corresponden al orden Agaricales, 12 al Orden Boletales, 2 al Orden Lycoperdales (Gasteromycetes), 5 al Orden Polyporales y 4 al Orden Schizophyllales.

Dentro de los 14 géneros se lograron identificar nueve especies.

La tabla 1 muestra los taxones determinados, de acuerdo a la clasificación taxonómica propuesta por Gams et al., 1998. 
Hongos basidiomycetes: Una contribución al conocimiento de 14 géneros en Norte de Santander

Tabla 1. Taxones fúngicos encontrados, según la clasificación propuesta por Gams et al., 1998

\begin{tabular}{|c|c|c|c|c|c|}
\hline & & ORDEN & FAMILIA & GENERO & ESPECIE \\
\hline \multirow{14}{*}{ 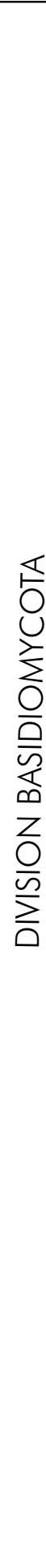 } & \multirow{14}{*}{ 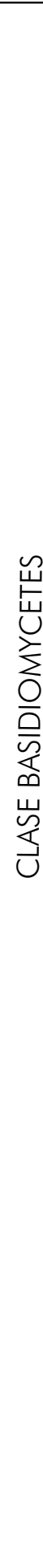 } & \multirow{10}{*}{ 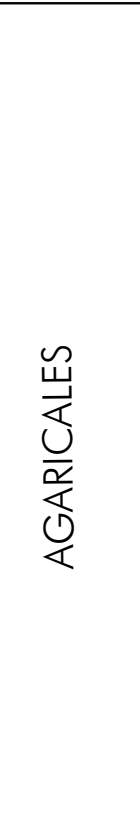 } & AGARICACEAE & Cystoderma & $\begin{array}{l}\text { Cystoderma } \\
\text { amianthinum }\end{array}$ \\
\hline & & & AMANITACEAE & Amanita & $\begin{array}{l}\text { Amanita } \\
\text { muscaria }\end{array}$ \\
\hline & & & COPRINACEAE & Psathyrella & Psathyrella sp. \\
\hline & & & HYGROPHORACEAE & Hygrocybe & $\begin{array}{l}\text { Hygrocybe } \\
\text { cantharellus }\end{array}$ \\
\hline & & & STROPHARIACEAE & Psilocybe & $\begin{array}{l}\text { Psilocybe } \\
\text { zapotecorum }\end{array}$ \\
\hline & & & \multirow{5}{*}{ TRICHOLOMATACEAE } & Armillaria & Armillaria sp. \\
\hline & & & & Clitocybe & Clitocybe sp \\
\hline & & & & Laccaria & $\begin{array}{l}\text { Laccaria } \\
\text { laccata }\end{array}$ \\
\hline & & & & Mycena & Mycena sp. \\
\hline & & & & Xeromphalina & $\begin{array}{l}\text { Xeromphalina } \\
\text { sp. }\end{array}$ \\
\hline & & $\begin{array}{l}\text { 崖 } \\
\text { 点 } \\
\text { ○ } \\
\end{array}$ & BOLETACEAE & Suillus & Suillus luteus \\
\hline & & 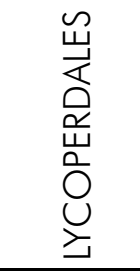 & LYCOPERDACEAE & Lycoperdon & $\begin{array}{l}\text { Lycoperdon } \\
\text { pyriforme }\end{array}$ \\
\hline & & 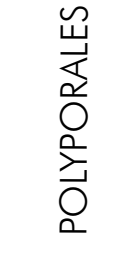 & LENTINACEAE & Lentinus & $\begin{array}{l}\text { Lentinus } \\
\text { crinitus }\end{array}$ \\
\hline & & 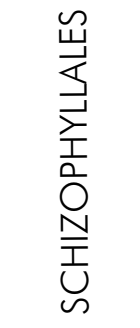 & SCHIZOPHYLLACEAE & Schizophyllum & $\begin{array}{l}\text { Schizophyllum } \\
\text { commune }\end{array}$ \\
\hline
\end{tabular}


Hongos basidiomycetes: Una contribución al conocimiento de 14 géneros en Norte de Santander

Se presenta una breve descripción de los géneros de acuerdo a Largent, D. \& Baroni T., (1988) y Pulido, (1982); y una breve descripción de las especies determinadas.

\section{ORDEN AGARICALES}

\section{Familia Agaricaceae}

En esta familia se identifico un género: Cystoderma y una especie Cystoderma amianthinum.

\section{Género Cystoderma Fayod. (1889)}

Cuerpos fructífero: pequeño a mediano, superficie del píleo y del estípite pulverulentas a granulosas. Píleo: de 0,4 - $8 \mathrm{~cm}$. de diámetro; superficie granulosa, pulverulenta o con escamas cónicas. Lamelas: adheridas, anexadas, adnadas, subdecurrentes, nunca libres, típicamente blancas o crema, algunas amarillentas, o con color de arcilla. Estípite: usualmente granulosos a polvoroso con o sin anillo. Esporada: blanca. Esporas: lisas de pared delgada, amiloides o inamiloides. Hábitat: terrestre o lignícola.

\section{Cystoderma amianthinum (Scop.) Fayod}

Píleo: 1,5-4cm. de diámetro, convexo; superficie seca, rugosa, granulosa; granulos color naranja sobre un fondo blanco; margen apendiculado. Contexto: blanco. Olor y sabor no distintivos. Lamelas: adnadas, cercanas, blancas, margen entero a finamente fimbriado. Lamelulas: de varias longitudes. Estípite: 2 - $4 \mathrm{~cm}$. de longitud, 0,1 - 0,6cm. de diámetro cerca al ápice, central, cilíndrico; superficie glabra en el ápice, granulosa hacia la base, concolora con la superficie del píleo o más claro, anillo superior peronado, granuloso, concoloro con la superficie del estípite. Esporada: blanca. Hábitat: gregario, sobre suelo rico en materia orgánica.

\section{Familia Amanitaceae}

En esta familia se identificó un género: Amanita y una especie: Amanita muscaria.
Género Amanita Pers. ex Hook. FI. Scot. 2:19. 1821.

Cuerpo fructífero: grande, carnoso, con escamas caducas. Píleo: hasta veinte centímetros de diámetro en algunas especies. Estípite: central sólido a hueco. Velo: universal bien desarrollado que deja una volva en la base del estípite y remanentes en la superficie del píleo, velo parcial que persiste como un anillo sobre el estípite. Lamelas: libres, blancas, margen de las lamelas generalmente con restos de velo parcial. Esporada: blanca crema ocasionalmente amarillo-verdoso. Esporas: globosas a cilíndricas de pared delgada. Pleurocistidios ausentes. Hábitat: suelo, hojarasca, bosques o áreas cercanas a árboles, la mayoría son micorrizicas.

Amanita muscaria (L. ex Fr.) Hook.

Píleo: de 5-10,5cm., plano a convexo, carnoso; superficie húmeda, color salmón en los bordes, anaranjado y rojo al centro cubierta con escamas blancas, borde liso, cutícula brillante; margen ligeramente estriado. Contexto: $1 \mathrm{~cm}$ de grosor, esponjoso, blanco, olor y sabor no distintivos. Lamelas: $0,8 \mathrm{~cm}$. de ancho, libres, cercanas, apretadas, blancas y borde liso. Estípite: 6,5$16 \mathrm{~cm}$., de longitud, central, carnoso, cilíndrico, blanco, liso, pero en la parte basal con escamas. Anillo: superior, membranoso, colgante, blanco. Volva: bien desarrollada, blanca. Esporada: blanca a crema. Esporas: ampliamente elípticas a globosas, de pared delgada, hialinas. Hábitat: sobre suelo.

\section{Familia Coprinaceae}

En esta familia se identificó un género: Psathyrella y una especie: Psathyrella sp.

Género Psathyrella (Fr.) Quél. Champ. Jura Vosg. 1: 178. 1872.

Cuerpo fructífero: pequeño a mediano. Píleo: de $5-7 \mathrm{~cm}$. de diámetro, carnoso, frágil, mayormente 
Hongos basidiomycetes: Una contribución al conocimiento de 14 géneros en Norte de Santander

convexo, cónico o acampanulado. Lamelas, adnadas o anexas. Estípite: central, fistuloso, frágil. Esporada: marrón oscura o marrón rojiza. Trama regular. Fíbulas presentes. Queilocistidios siempre presentes. Esporas: generalmente con poro germinal, que se decoloran en presencia de acido sulfúrico concentrado. Hábitat: materia en descomposición, hojarasca, musgos, suelo o sobre otros hongos.

Psathyrella sp.

Píleo: 3,5-6,5 cm., campanulado con centro obtuso; superficie húmeda, mate, glabra, lisa y suave al tacto, de color naranja tornándose marrón oscuro con la edad; margen recurvado entero. Contexto: blanco hacia la cutícula del píleo y naranja hacia el estípite. Olor poco perceptible a inodoro, sabor insípido. Himenóforo: concoloro con el píleo. Lamelas: muy juntas, libres; margen entero. Estípite: 4,5- 5,5 cm. de longitud, central, cilíndrico, curvo hacia la base; superficie de color marrón a naranja, húmeda, sedosa; interior sólido hacia el píleo y hueco hacia la base, quebradizo a cartilaginoso, sin anillo. Esporada: negro-parduzca. Hábitat: cespitoso, sobre tronco muerto y en lugares sombreados.

\section{Familia Hygrophoraceae}

En esta familia se identificó un genero: Hygrocybe y una especie: Hygrocybe cantharellus.

Género Hygrocybe (Fr.) P. Kumm. (1871)

Cuerpo fructífero: pequeño a mediano. Píleo: $(0,5-) 1-8(-12) \mathrm{cm}$. de diámetro, color brillante amarillo, rojizo o verde, raramente de color grisáceo o marrón, usualmente limpio, brillante, glabro y a veces lubricado a glutinoso o menormente escuamuloso en estado seco. Lamelas: sinuadas, adnadas a decurrentes. Estípite: central, frágil y concoloro al píleo. Esporada: blanca. Esporas: lisas, inamiloides. Hábitat: sobre humus, suelo.
Higrocybe cantharellus. (Schewein.) Muril.

Píleo: 1-1,5 cm. de diámetro, plano con una depresión pequeña hacia el centro; superficie húmeda, viscida o pegajosa al tacto, brillante, glabra, higrófana, amarillo claro al borde y oscuro hacia el centro, margen entero a curvado. Lamelas: angostas y cercanas. Estípite: central, corto, delgado, $1-2 \mathrm{~cm}$ de longitud, 0,2 cm. de grosor, superficie lisa, glabra, concolora con el píleo hacia el ápice, pero marrón oscura hacia la base. Esporada: blanca. Hábitat: sobre troncos muertos, se encuentra disperso y en lugares sombreados.

\section{Familia Strophariaceae}

En esta familia se identificó un género: Psilocybe y una especie: Psilocybe zapotecorum

Género Psilocybe (Fr.) P. Kumm. (1871)

Cuerpo fructífero: pequeño. Píleo: 0,5-3 (-4) cm., convexo hasta cónico campanulado, a menudo, umbonado o papilado; superficie subviscida a viscida, color marrón amarillento a marrón. Lamelas: subadheridas o sinuadas. Estípite: central, delgado, quebradizo, anillo presente o ausente, si lo presenta es fugaz. Esporada: marrón violácea a marrón púrpura. Fíbulas presentes, con o sin pleurocistidios, queilocistidios generalmente abundantes formando una banda estéril en el borde de la lámela. Esporas: frecuentemente lenticulares marrón amarillentas, nunca negras, lisas, con poro germinal. Hábitat: estiércol, musgo, hojarasca, materia orgánica en descomposición.

\section{Psilocybe zapotecorum R. Heim.}

Píleo: 0,6-1cm., campanulado a papilado; superficie estriada, seca, glabra; margen del píleo apendiculado. Contexto: 0,1 cm. grosor, de color marrón oscuro. Lamelas: blancas, adnadas, distantes, delgadas; margen entero. Estípite: $3,5 \mathrm{~cm}$ de longitud, $0,1 \mathrm{~cm}$. de grosor, central, cilíndrico a flexuoso, curvo, 
Hongos basidiomycetes: Una contribución al conocimiento de 14 géneros en Norte de Santander

superficie de color marrón oscuro, fibrilosa. Esporada: café violácea. Esporas: elipsoides, oblongas a ovoides con poro germinal, lisas. Hábitat: sobre troncos en descomposición.

\section{Familia Tricholomataceae}

En esta familia se identificaron cinco géneros: Armillaria, Clitocybe, Laccaria, Mycena, Xeromphalina.

\section{Género Armillaria (Fr.) Staude (1857)}

Cuerpo fructífero: mediano a grande parecido a Tricholoma, pero con un anillo o zona anular. Píleo: 3-15 (-20) cm. de diámetro, plano convexo; superficie glabra, fibrilosa. Lamelas: anexas, sinuadas, de color blanco a gris pálido. Estípite: carnoso, con anillo que puede ser membranoso o fibriloso, coloreado o concoloro con el píleo. Esporada: blanca. Esporas: lisas, amiloides. Hábitat: sobre materia orgánica en descomposición, humus.

\section{Armillaria sp.}

Píleo: 0,5-6 cm. de diámetro, plano convexo, centro umbonado; superficie mate, lisa y seca, color marrón claro a beige; margen recto, estriado. Contexto: continuo, no se separa claramente del estípite, blanco hacia el centro y beige hacia el margen. Olor poco perceptible, sabor más o menos picante. Himenóforo: concoloro con el píleo. Lamelas juntas adnadas a subdecurrentes. Estípite: 3-5,5 cm. de longitud, central, cilíndrico; superficie de color marrón claro en el ápice a marrón oscuro hacia la base quebradizo; interior sólido. Anillo: apical, blanco y membranoso. Esporada: blanca. Hábitat: cespitoso. Se encontró sobre troncos en descomposición cerca de lugares húmedos (quebrada), sombreado, y sobre musgo.

\section{Género Clitocybe (Fr.) Staude, 1857}

Cuerpo fructífero: de pequeños a grandes. Píleo: 0,5-3 cm. de diámetro, convexo, plano, depreso o infundibuliforme; superficie glabra, fibrilosa o canescente. Lamelas: adnadas a decurrentes, delgadas. Estípite: central a excéntrico, carnoso o fibroso. Esporada: blanca, crema a rosácea. Esporas: lisas, ornamentadas, con pequeñas verrugas, inamiloides. Hábitat: suelo, humus, hojarasca.

\section{Clitocybe sp.}

Píleo: 1 - $4 \mathrm{~cm}$. de diámetro, plano a depreso, superficie seca a húmeda, higrofana, glabra, finamente tomentosa a ligeramente lanuda, centro blanco y escamas amarillas muy pálido, margen apendiculado, Contexto: blanco. Olor suave. Lamelas: menos de $0,1 \mathrm{~cm}$. de ancho, adnadas, decurrentes, blancas; margen entero. Estípite: 2 - $5 \mathrm{~cm}$. de longitud, 0,2 $0,5 \mathrm{~cm}$. de diámetro cerca al ápice, central, cilíndrico, curvado. Esporada: blanca. Hábitat: gregario, sobre humus.

\section{Género Laccaria Berk \& Broome. (1883)}

Cuerpo fructífero: mediano a grande, no revive por hidratación después de seco. Píleo: convexo a deprimido, carnoso. Lamelas: adnadas gruesas, cercanas a subdistantes. Estípite: central, hueco. Trama himenifera: regular, hifas con fibulas, pleurocistidios ausentes. Esporada: blanca. Esporas: generalmente globosas, ocasionalmente elípticas, equinuladas, a veces lisas, hialinas e inamiloides. Hábitat: terrestre, sobre humus en varios tipos de bosque.

Laccaria laccata (Scop.) Fr.

Píleo: 1 - 3,5 cm. de diámetro, esférico, convexo, superficie seca, lisa y brillante, centro deprimido, margen recto, glabro, color beige-rosa a rojo ladrillo brillante, unión del contexto homogéneo, color concoloro al píleo y al himenóforo. Lamelas: distantes, anchas, desiguales, poco decurrentes de color rosado claro. Estípite: central, torcido, de color marrón claro, 3 - $9 \mathrm{~cm}$. de longitud, largo, plano, cartilaginoso y fino, textura sedosa, suave y brillante, contexto: beige claro o rosado, hueco. Olor fuerte, 
Hongos basidiomycetes: Una contribución al conocimiento de 14 géneros en Norte de Santander

sabor indescriptible. Esporada: blanca. Hábitat: sobre el suelo rico en materia orgánica o humus, lugar sombreado.

\section{Género Mycena (Pers.) Roussel (1806)}

Cuerpos fructíferos: frágiles y blandos típicamente pequeños a medianos. Píleo: de 0,1 $-5 \mathrm{~cm}$. de diámetro a menudo produciéndose en gran número esparciéndose por el sustrato, cónico, umbonado, campanulado o meramente convexo al principio, ligeramente depreso, a menudo transparente, estriado sobre la margen, margen decurvada o plana. Lamelas: generalmente adheridas típicamente adnadas, anexas, ocasionalmente decurrentes. Estípite: frágil, 1-3 mm. de grueso, sin velo; produce escaso a abundante látex cuando se corta, superficie glutinosa. Esporada: blanca. Esporas: lisas, amiloides o inamiloides, queilocistidiios presentes. Hábitat: sobre sustrato vivo o en descomposición, musgos, helechos, detritus de confieras y suelos arenosos.

\section{Mycena sp.}

Píleo: 0,5 - 2,8cm. de diámetro, cónico, convexo, umbonado, color marrón grisáceo, oscuro hacia el centro y pálido hacia el margen, margen casi blanco, ligeramente estriado a crenado. Contexto: $1 \mathrm{~cm}$. de grosor, blanco grisáceo, frágil, cartilaginoso, olor alcalino, sabor ligeramente ácido. Lamelas: blancas, 0,2 $0,3 \mathrm{~cm}$. de ancho adnadas a subdecurrentes, margen blanco. Estípite: 1,8 - 9,5cm. de longitud largo y torcido, grosor $0,1 \mathrm{~cm}$. color marrón oscuro, concoloro al píleo, central, flexuoso, cilíndrico, superficie húmeda brillante, hueco. Esporada: blanca. Hábitat: gregario a cespitoso, sobre madera en descomposición.

\section{Género Xeromphalina Kühner \& Maire (1934)}

Cuerpos fructíferos: pequeños a medianos. Pileo: 0,2 a 3cm de diámetro en una especie alcanza hasta $7 \mathrm{~cm}$., convexo a acampanado, a menudo llega a ser plano y hundido sobre el disco, amarillento a amarillento-parduzco u opaco-ocráceo, ferruginoso, pardizo u oliváceo-marrón, en muchas especies estriado, translucido, glabro, fibruloso o granuloso, típicamente flexible, duro. Lamelas: amplias, decurrentes, adnadas, amarillentas. Estípite: delgado 3 a $8 \mathrm{~mm}$ de diámetro cerca al ápice, oscuroparduzco, duro, tomentoso cerca de la base. Hábitat: sobre hojas en descomposición de coníferas y de árboles maderables. Esporas: lisas, elipsoidales, oblongas, cilíndricas, amiloides. Hifas en alguna taxa erectas y sus ápices formando palizadas, a menudo con pigmentos incrustados rojizos a rojizo-pardizos.

Xeromphalina sp.

Pileo: 0,6 - 2,8cm de diámetro, convexo depreso en el centro a subumbilicado; superficie estriada, glabra a finamente fibrilosa, higrófana, amarillo claro en el margen y amarillo oscuro hacia el centro; margen entero e incurvado. Lamelas: cercanas, angostas, adnadas, blancas; margen entero. Estípite: 1,5 - 5 $\mathrm{cm}$. de longitud, 0,1-0,5cm de diámetro cerca al ápice, central, subbulboso; superficie fibriloso a pubescente, concolora con la superficie del píleo en el ápice pero más oscuro hacia la base. Esporada: amarillo claro. Hábitat: sobre musgo, solitario o en pequeños grupos, en suelos con alto contenido de materia orgánica o humus.

\section{ORDEN BOLETALES}

Se identificó una familia, un género y una especie.

Familia Boletaceae

En esta familia se identificó un género: Suillus y una especie: Suillus luteus.

\section{Género Suillus Gray, 1821}

Cuerpos fructíferos: grandes, putrescibles. Píleo: de colores variados, sin restos, viscoso y pegajoso, muy carnoso. Estípite: variado, en algunos casos fibroso o membranoso, con anillos gelatinosos o sin ellos. 
Hongos basidiomycetes: Una contribución al conocimiento de 14 géneros en Norte de Santander

Himenio: compuesto de tubos soldados entre si, suele ser de colores claros y brillantes amarillos, verdes. Esporada: de variados colores, desde blanca, marrón hasta roja. Hábitat: bosques de coníferas.

Suillus luteus (L.) Gray.

Píleo: 6 - $8 \mathrm{~cm}$. de convexo a plano, superficie viscosa y glutinosa, de color marrón amarillento, muy carnoso. Tubos: estrechos, adnatos a decurrentes, largos, de color amarillo pálido y con el tiempo amarillo oliva. Poros: estrechos, angulosos y de color amarillo pálido o amarillo oliva. Estípite: de $4-7 \mathrm{~cm} \times 1$ $2.5 \mathrm{~cm}$, cilindrico, con gránulos cerca del ápice, flexuoso, blanco, pubescente. Anillo: blanco, resistente, membranoso de 6 a $10 \mathrm{~cm}$. Carne: blanda, blancoamarilla; olor afrutado y sabor dulce Esporada: de color ocre canela. Hábitat: sobre suelo y cerca de troncos muertos a la sombra.

\section{ORDEN LYCOPERDALES}

Los especimenes de Gasteromycetos hallados se reportan como Lycoperdanas.

Género Lycoperdon Pers. (1801)

Cuerpo fructífero: mediano a grande, que permanece cerrado y se abre después de la maduración de las esporas; piriforme a subgloboso. Estípite: infértil corto y grueso. Gleba: de tipo coraloide, que se caracteriza, por la existencia de numerosa proliferaciones cilíndricas o espatuladas, que crecen a partir de una porción estéril de la gleba, y sobre las cuales se desarrolla la parte fértil o esporífera. Esporada: desde amarilla hasta pardusca. Hábitat: lignícola, preferiblemente bosque de coníferas.

\section{Lycoperdon pyriforme. Schaeff.}

Carpóforo: subgloboso a globoso (ver Foto), de 2,5-6,0 cm. de diámetro, color de blanco a beige y café claro, presenta manchas o espinas marrón oscuro que se desprenden fácilmente. Estípite: corto, grueso y con granulaciones que se desprenden fácilmente al tocarlo, de $2-3 \mathrm{~cm}$. de longitud y 1 - $3 \mathrm{~cm}$. de diámetro. Gleba: blanca a beige, carnosa, olor penetrante. Esporada: café. Esporas esféricas, verrugosas. Sabor y olor a madera podrida. Hábitat: suelo.

\section{ORDEN POLYPORALES}

Se colectaron en total cinco muestras, las cuáles fueron descritas y caracterizadas, permitiendo identificar una familia y un género. La familia identificada es Lentinaceae.

\section{Familia Lentinaceae}

En esta familia se identificó un género Lentinus y una especie Lentinus crinitus.

Género Lentinus Fries, Syst. Orb. Veg. 77. 1825.

Cuerpo fructífero: desde pequeños hasta grandes, Píleo: 0,5-30 (-40) cm. en diámetro, correoso, con hifas esqueléticas de pared gruesa, convexo, plano o con depresión central. Lamelas: adnadas o decurrentes. Estípite: central hasta excéntrico Velo: algunas veces presente pero fugaz. Esporada: blanca, amarillenta hasta anaranjado. Esporas: lisas, elipsoides, elipsoides oblongas o cilíndricas, inamiloides con o sin metuloides. Hábitat: lignícola.

Lentinus crinitus (Linn.: Fr.)

Píleo: 1 - 4cm. de diámetro, plano a plano convexo, con una depresión central o infundibuliforme, superficie estriada de color crema a marrón oscuro, margen recurvado y con presencia de pelos. Himenóforo: lamelas, de color amarillo pálido y con lamelulas de diferentes longitudes. Estípite: central o excéntrico y de consistencia correosa, cilíndrico, superficie escuamulosa, de color amarillo pálido, longitud de 1 - 2cm. Esporada: blanca. Hábitat: sobre tronco caído. 
Hongos basidiomycetes: Una contribución al conocimiento de 14 géneros en Norte de Santander

\section{ORDEN SCHIZOPHYLLALES}

Se identificó una familia y un género.

Familia Schizophyllaceae

En esta familia se identificó el genero: Schizophyllum y la especie: Schizophyllum comune.

Género Schizophyllum Fr. (1821).

Cuerpos fructíferos: pequeños, tiene forma de abanico o pequeña concha. Píleo: dimidiado de $1-4 \mathrm{~cm}$. de diámetro duro en textura, pálido a grisáceo o grisáceo oscuro. Superficie superior vellosa con pelos muy erizados de color gris. Lamelas: margen fimbriado a ligeramente pubescente, dispuestas radialmente, café grisáceo a gris. Estípite: ausente o muy reducido. Esporada: blanca. Esporas: cilíndricas, de pared delgada, inamiloides. Hábitat: sobre materia en descomposición, en bosques de coníferas.

\section{Schizophyllum commune Fr.}

Carpóforo: pileado, pseudoestipitado, imbricado. Píleo: de $1-4 \mathrm{~cm}$. En forma de concha o flabeliforme, consistencia correosa, superficie lanosa de color blanco a beige, margen lobulado. Himenóforo: con falsas lamelas, constituidas por pliegues dobles y bifurcados, de color rosado a gris violeta. Estípite: ausente. Esporada: blanca. Hábitat: sobre troncos.

Figura 3. Especimenes determinados

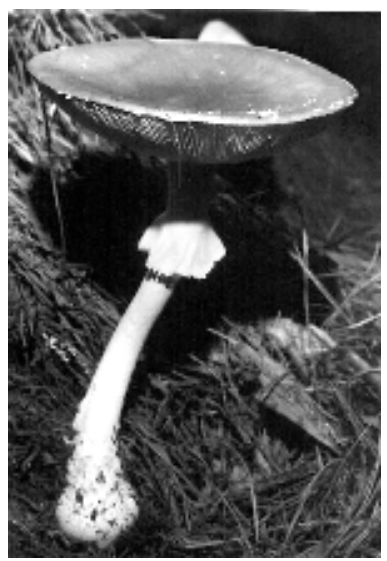

Amanita muscaria

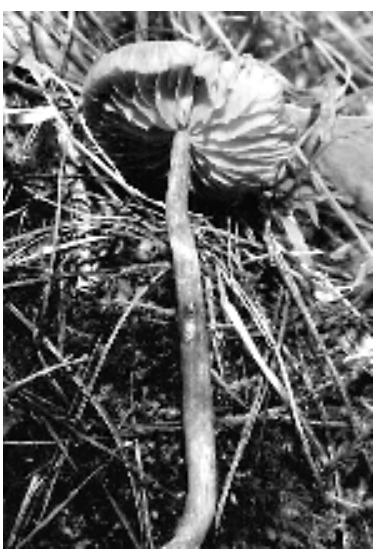

Laccaria laccata

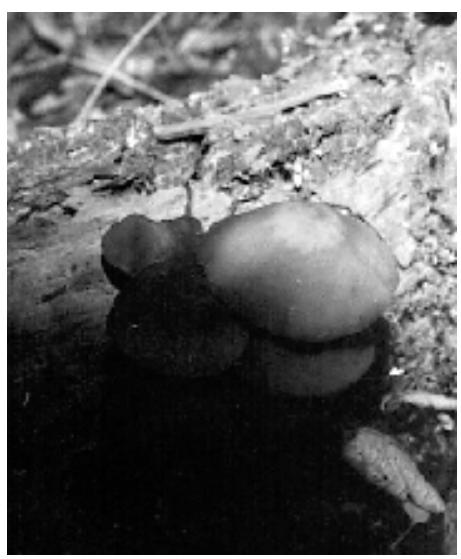

Psathyrella sp.

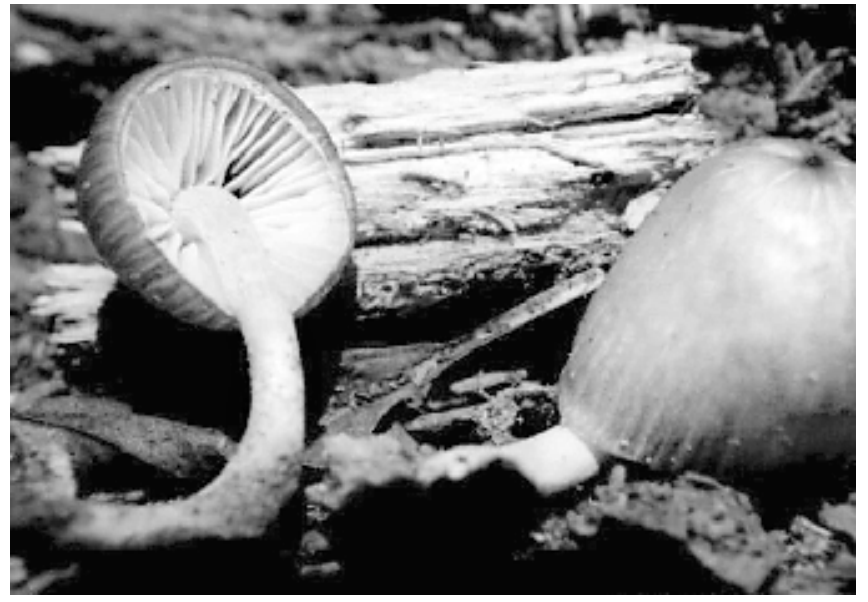

Mycena sp.

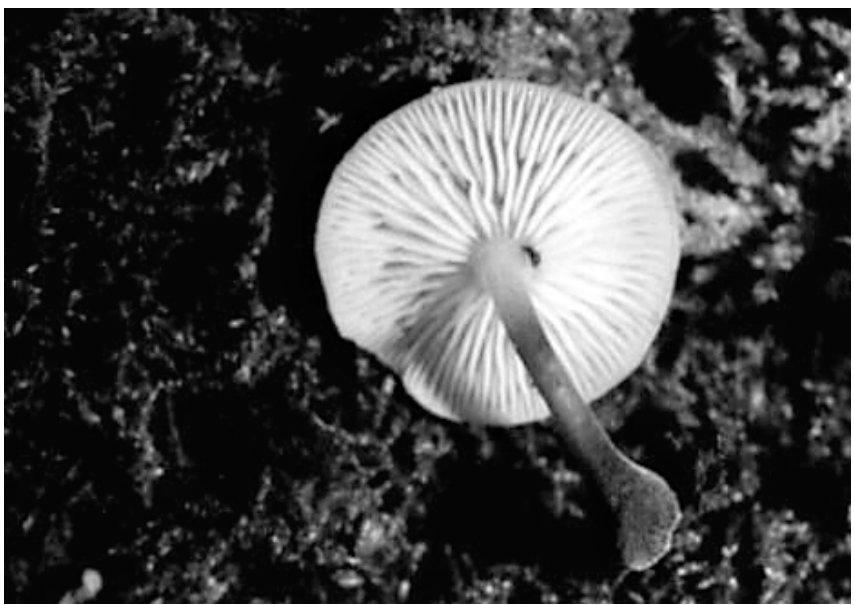

Xeromphalina sp. 
Hongos basidiomycetes: Una contribución al conocimiento de 14 géneros en Norte de Santander
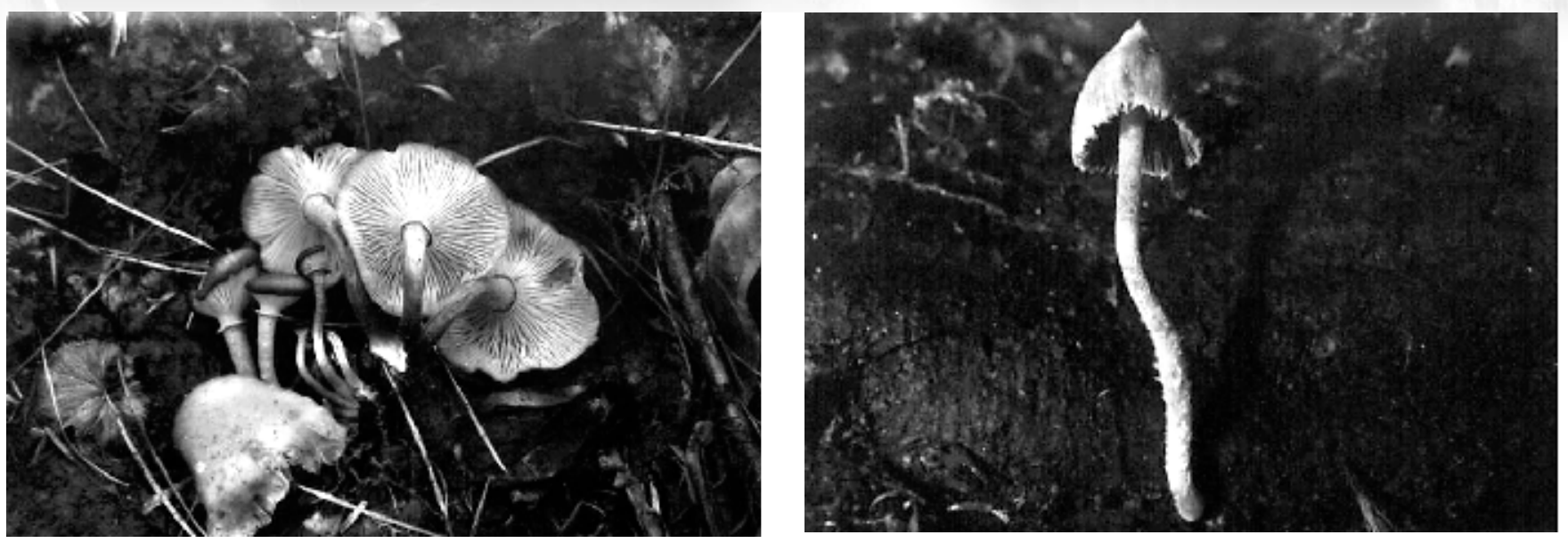

Armillaria sp

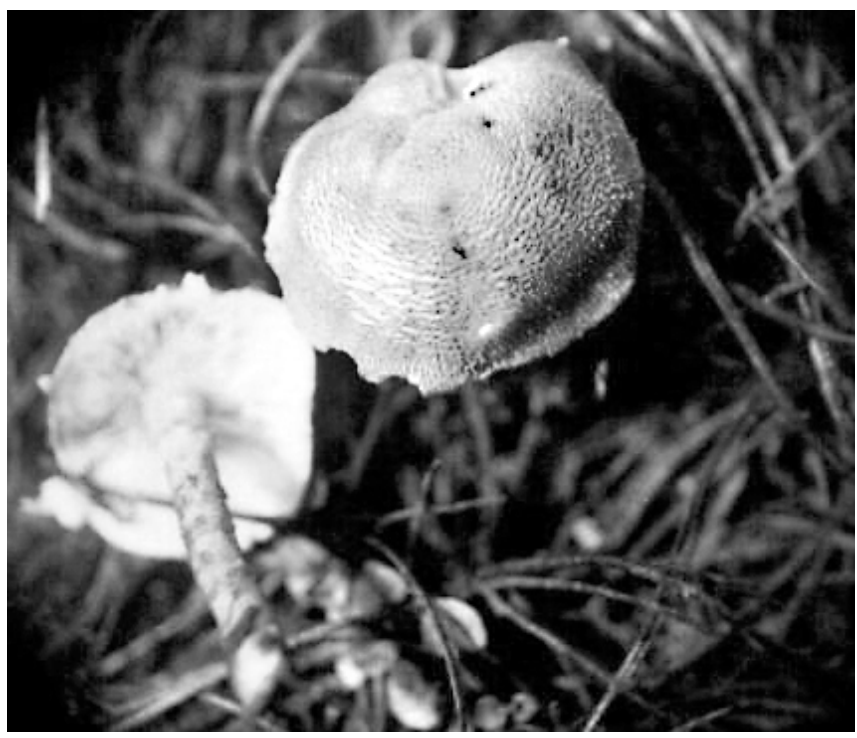

Cystoderma amiathinum.

Psilocybe zapotecorum

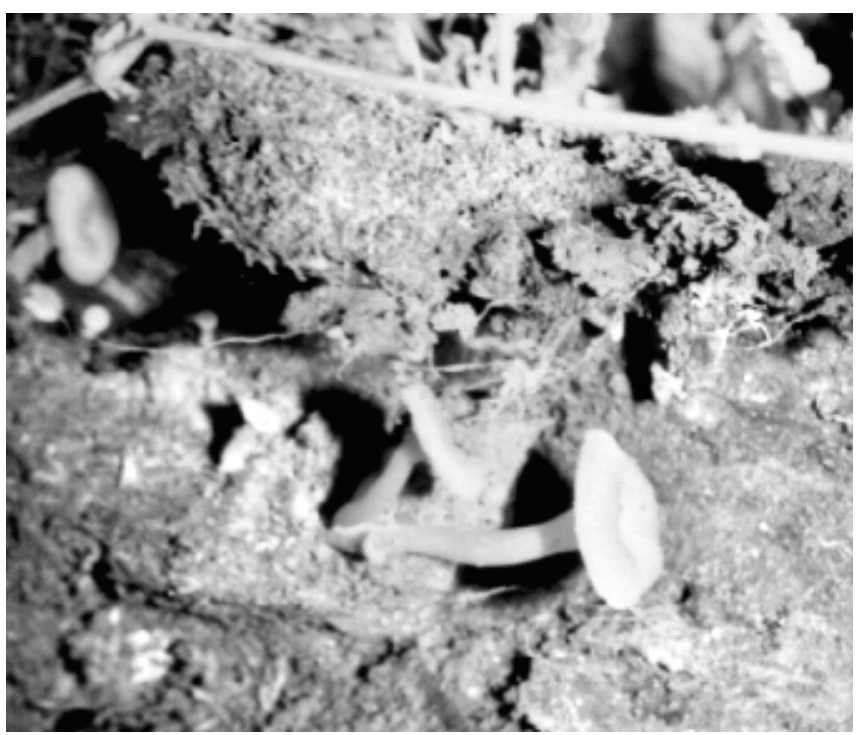

Hygrocybe cantharellus

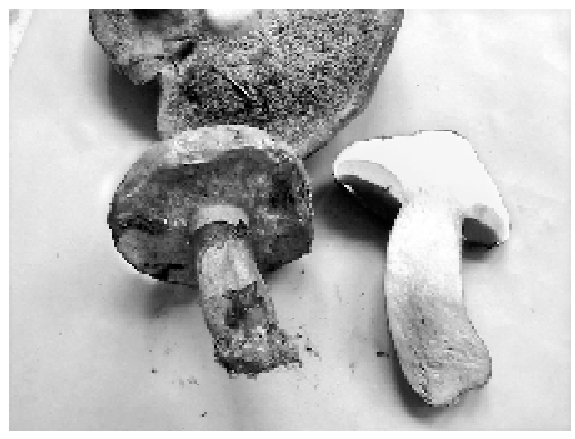

Suillus luteus

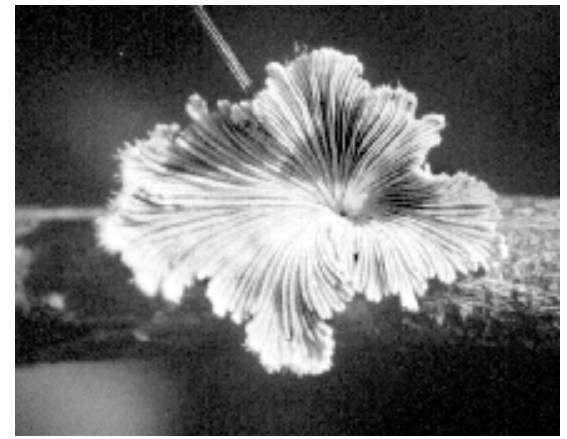

Schizophyllum commune

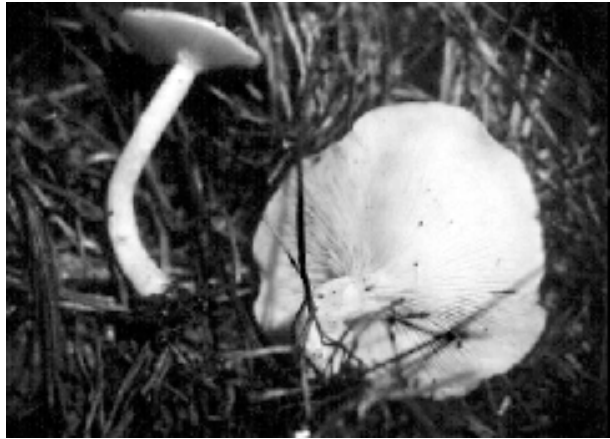

Clitocybe sp. 
Hongos basidiomycetes: Una contribución al conocimiento de 14 géneros en Norte de Santander
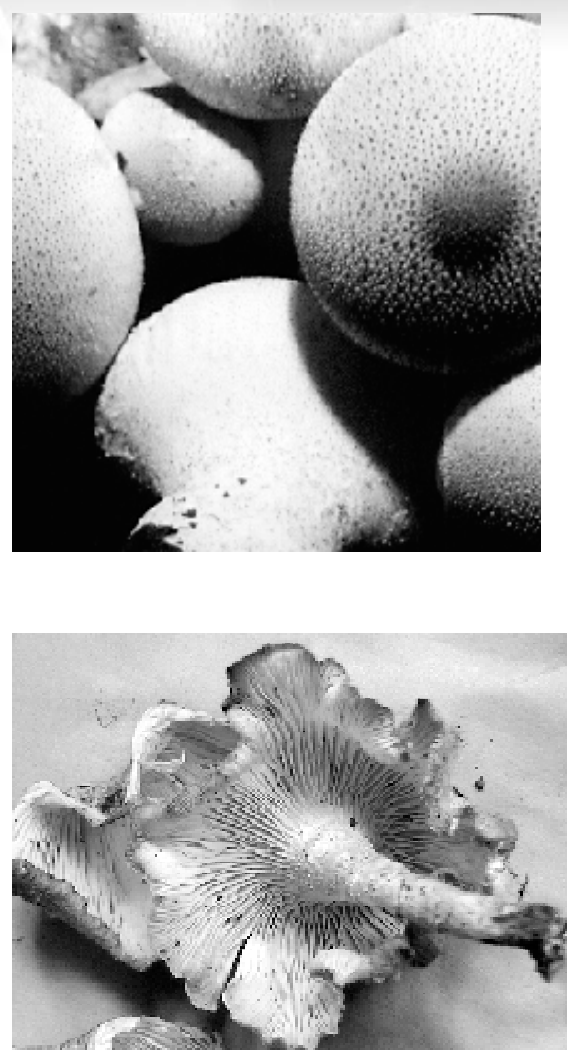

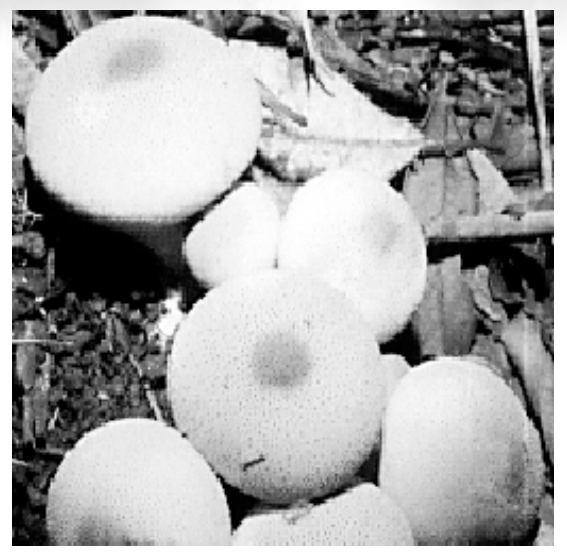

Lycoperdon pyriforme

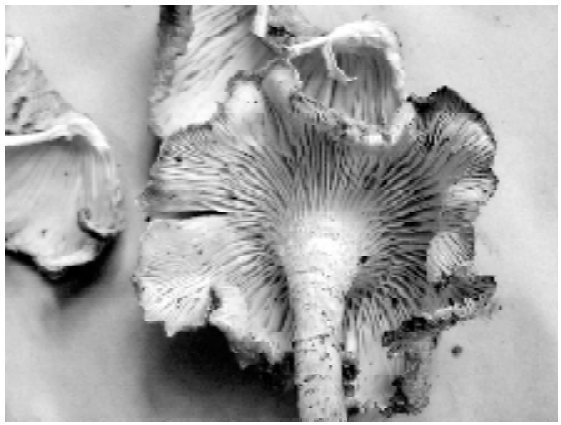

Lentinus crinitus
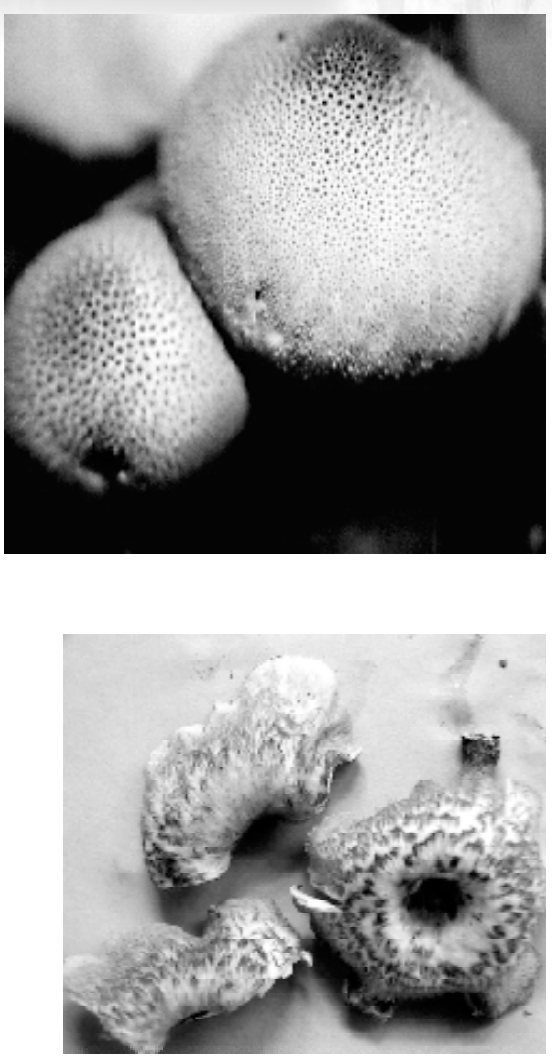

\section{CONCLUSIONES}

El presente estudio preliminar identifica 14 géneros, pertenecientes a 9 familias dentro de los Ordenes Agaricales, Boletales, Polyporales, Schizophyllales y el grupo Gasteromycetes.

Con base en el número de especimenes recolectados, en el bosque de niebla del Alto de Mejué, zona de vida cuyo bioma corresponde a un bosque Húmedo Montano Bajo (bh-MB), o bosque andino, los ordenes de mayor población son Agaricales, Boletales y en menor presencia los Gasteromycetes.

El presente estudio es precedente, para desarrollar trabajos similares en el mismo bosque o en bosques de niebla (andinos) semejantes, para corroborar diversidad y riqueza de esta micoflora.

\section{AGRADECIMIENTOS}

La autora agradece al Fondo de Investigaciones Universitarias (FINU) de la Universidad Francisco de Paula Santander, por el apoyo financiero.

\section{BIBLIOGRAFÍA}

AINSWORTH, D. L., KIRK, P. M., SUTTON, B. C. y PEGLER, D.N. 1995. Dictionary of the fungi. Edic. $8^{a}$. University Press. Cambridge.

ALEXOPOULOS C. J. Y MIMS W. 1985. Introducción a la Micología. Ed. Omega.

CASTRO, Marisa. 2003. Setas de Andalucia.

GOMEZ, P. Luis D. 2000 Basidiomycetes de Costa Rica: Xerocomus, Chalciporus, Pulveroboletus, Boletellus. 
Hongos basidiomycetes: Una contribución al conocimiento de 14 géneros en Norte de Santander

FRANCO-MOLANO, Ana Esperanza. VASCO-PALACIOS, Aída Marcela. LOPEZ-QUINTERO, Carlos Alberto y BOEKHOUT, Teun. 2005. Macrohongos de la región del medio Caquetá-Colombia.

FRANCO-MOLANO, Ana Esperanza. ALDANAGOMEZ, Ruth. HALLING, Roy E. 2000. Setas de Colombia. Editorial Universidad de Antioquia.

FRANCO-MOLANO, Ana Esperanza \& URIBE-CALLE, Emilce. 2000. Hongos Agaricales y Boletales de Colombia. Biota Colombiana 1 (1) 25-43.

GAMS, W., E. S. Hoekstra \& A. Aproot. 1998. CBS Course of Mycology 4th ed. CBS, Baarn, Holanda. 165 pp.

LARGENT, D. \& BARONI, T. 1988. How to Identify Mushrooms To Genus VI: Modern Genera. Department of Biological Sciences. Cortland, New York.

LARGENT, D., D. Johnson \& R. Watling. 1977. How the identify mushrooms to genus III: Microscopic features Mad River Press, Eureka. California. 147 pp.

LLIMONÁ, Xavier. 2004. Hongos, en Botánica. Ed. McGraw-Hill Interamericana. Madrid. España, 2. ed.

NIEVES-RIVERA, A., SANTOS FLORES, C., \& BETANCOURT, C. Notas sobre los Agaricales del páramo de Guasca, Departamento de Cundinamarca, Colombia. Caldasia 19 (1-2). pp 349-351.

PULIDO, M. 1982. Estudios en Agaricales Colombianos. Instituto de Ciencias Naturales. Universidad Nacional. Bogotá Colombia.

VALENZUELA VANEGAS, Mario, CARREÑO Fredy \& OSORIO JACOME, Alfredo. 2004. Identificación Etnobotánica de la flora medicinal, agroindustrial e industrial del Bosque de Niebla Alto de Mejué, Municipio de Chinacota, Norte de Santander. Respuestas, Año 9 Vol. 2. UFPS.
VELASQUEZ, Luis Fernando. SALDARRIAGA, Yamilé, PINEDA, Fabio \& GARCIA, Gustavo. 1998. Hongos de Antioquia. Editorial Universidad de Antioquia.

Recibido : Julio 21 de 2006

Aceptado : Diciembre 10 de 2006 